
W.1

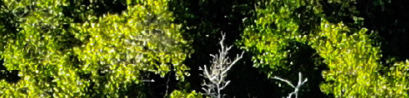

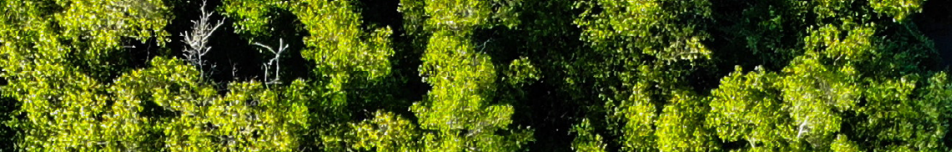

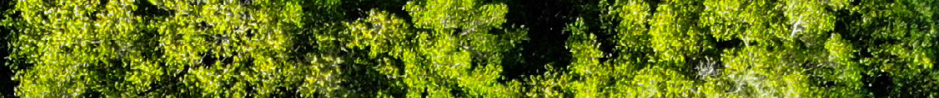

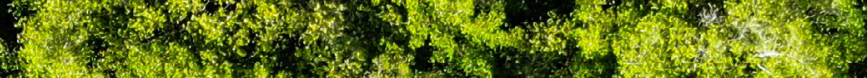

1.7.

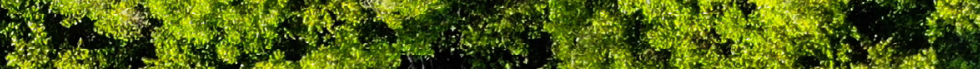

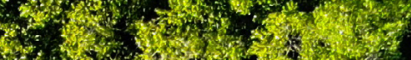

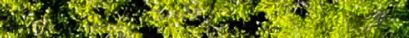

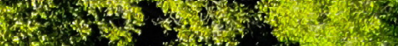

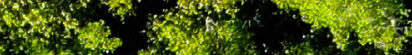

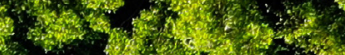

1.t.

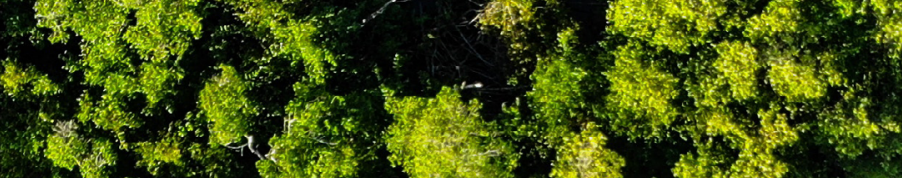

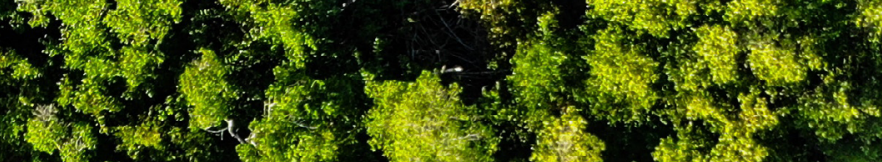

(1)

on

N.

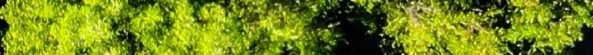

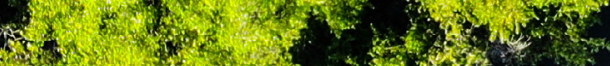

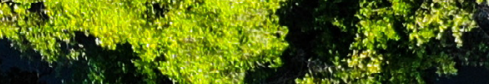

s. ar.

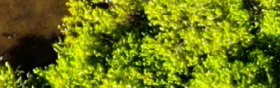

trots 3

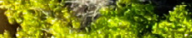

4.

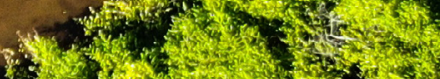

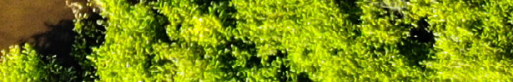

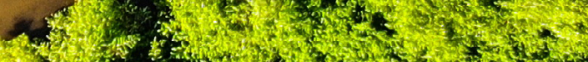
4.

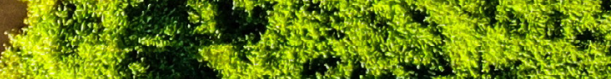

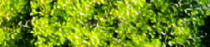

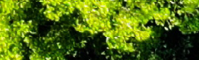

W. . n:

8

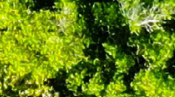

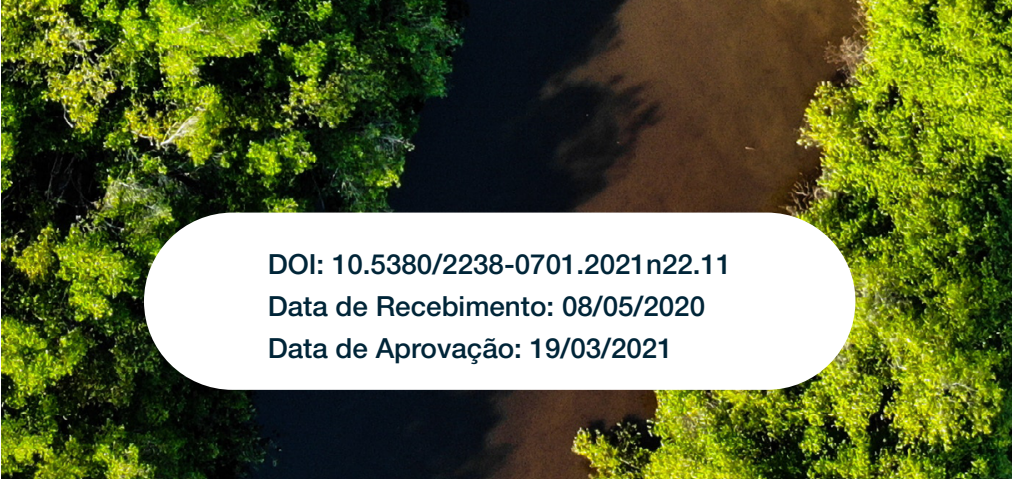

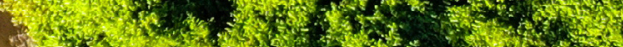
m.t. क.

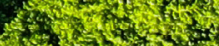

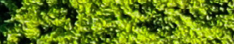

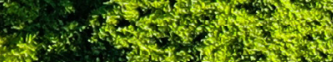

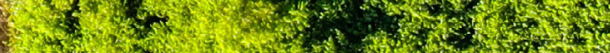
S.

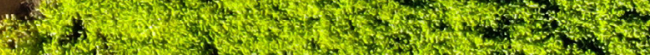
H.

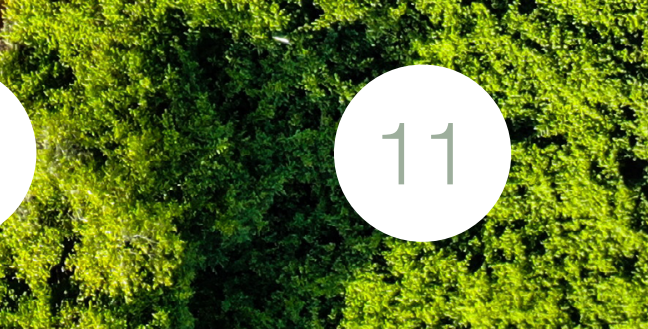


"Um Brasil quase desconhecido habitado por homens gigantes": As representações do povo Ashaninka na reportagem A Última Fronteira de Vinícius Dônola 


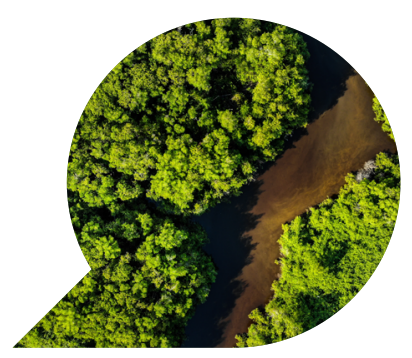

\section{"Um Brasil quase desconhecido habitado por homens gigantes": As representações do povo Ashaninka na reportagem A Última Fronteira de Vinícius Dônola}

"An almost unknown Brazil inhabited by giant men": The representations of the Ashaninka people in the article A última fronteira by Vinícius Dônola

"Un Brasil casi desconocido habitado por hombres gigantes": las representaciones del pueblo Ashaninka en el artículo A última fronteira de Vinícius Dônola

FRANCIELLE MARIA MODESTO MENDES ${ }^{1}$

Resumo: O objeto da análise deste artigo é a reportagem "A última fronteira", que discorre sobre os povos Ashaninka, com texto de Vinícius Dônola e imagens de Thompson Lee Brito. Foi ao ar em 20 de maio de 2013 na Record TV. O objetivo é discutir de que forma esta reportagem articula as representações sobre os povos indígenas Ashaninka, que vivem na fronteira do Brasil-Acre/Peru, e a Amazônia brasileira acreana. A pesquisa tem cunho bibliográfico e usa como suporte os seguintes autores: Homi Bhabha (2013), Manuela

1 Doutora em História Social (USP), Mestre em Letras (UFAC), graduação Letras e Jornalismo, professora do curso de Comunicação Social/Jornalismo, da Pós-graduação em Letras e do Mestrado Profissional em História da Universidade Federal do Acre. 
Carneiro Cunha (2012, 2016), Gerson Albuquerque (2016), entre outros. Os seguintes aspectos de análise são levados em consideração como percurso metodológico: as noções de inferno/paraíso tropical; a ideia de vazio, monotonia e distanciamento; e a comparação dos espaços floresta/cidade não amazônica. Todos esses itens se articulam em torno das ideias de atraso/progresso, tradição/moderno, presente/passado que permeiam a formação da Amazônia brasileira acreana e de suas gentes, sobretudo, indígenas.

Palavras-chave: Representações; Ashaninka; Jornalismo.

Abstract: The object of this article is "A última fronteira," which discusses the Ashaninka peoples, with text by Vinícius Dônola and images by Thompson Lee Brito. It was published on May 20 ${ }^{\text {th }}, 2013$, on Record TV. The objective is to discuss how this article articulates the representations about the Ashaninka indigenous peoples, who live on the Brazil-Acre/Peru border, and the Acre Brazilian Amazon. The research is bibliographic and uses the following authors as support: Homi Bhabha (2013), Manuela Carneiro Cunha (2012, 2016), Gerson Albuquerque (2016), among others. The following aspects of analysis are the notions of hell/tropical paradise, the idea of emptiness, monotony, and distance, and the comparation of non-Amazonian forest/city spaces. All these items are articulated around the concepts of delay/progress, tradition/ modern, present/past that permeate the formation of the Acrean Brazilian Amazon and its people, above all, indigenous people.

Keywords: Representations; Ashaninka; Journalism.

Resumen: El objeto de este artículo es el artículo "A última frontera", que trata sobre los pueblos Ashaninka, con texto de Vinícius Dônola e imágenes de Thompson Lee Brito. Se emitió en 20 mayo de 2013 en Record TV. El objetivo es discutir cómo este artículo articula las representaciones sobre los pueblos indígenas Ashaninka, que viven en la frontera Brasil-Acre/ Perú, y la Acre Amazonia brasileña. La investigación es bibliográfica y utiliza como soporte a los siguientes autores: Homi Bhabha (2013), Manuela Carneiro Cunha (2012, 2016), Gerson Albuquerque (2016), entre otros. Se tienen en cuenta como camino metodológico los siguientes aspectos de análisis: las nociones de infierno / paraíso tropical; la idea de vacío, 
monotonía y distancia; y la comparación de espacios de bosque / ciudad no amazónicos. Todos estos elementos se articulan en torno a las ideas de retraso / progreso, tradición / moderno, presente / pasado que impregnan la formación de la Amazonia brasileña acreana y su gente, sobre todo, los indígenas.

Palabras-clave: Representaciones; Ashaninka; Periodismo.

"Estrela d'Água me molha

Tudo que ama e chora

Some na curva do rio

Tudo é dentro e fora

Minha Floresta de jóia" (Milton Nascimento e Márcio Borges) ${ }^{2}$

Em 2013, o jornalista Vinícius Dônola esteve no Acre para gravar uma série de reportagens especiais para a Record TV. Acompanhado do repórter cinematográfico Thompson Lee Brito, Dônola produziu seis matérias para o Jornal da Record ${ }^{3}$ sobre os mais variados assuntos, tais como: os Ashaninka ${ }^{4}$, os geoglifos, os imigrantes haitianos, a violência no campo, os 25 anos de morte de Chico Mendes e a produção de peixe em cativeiro no Acre.

O objeto de estudo deste artigo é a reportagem jornalística intitulada "A última fronteira" sobre os povos Ashaninka que foi ao ar em 20 de maio de 2013. Segundo dados da Comissão Pró-índio ${ }^{5}$, essa etnia é originária do Peru. Em 2020, vivem aproximadamente 3000 indígenas no Acre. No rio Amônia, que é o local visitado pelo jornalista, mora uma média de 800 pessoas. A língua falada é o Ashaninka, do tronco linguístico Aruak. E a principal fonte de renda deste povo é o artesanato.

\footnotetext{
2 Benke é o nome de uma canção de Milton Nascimento e Márcio Borges lançada no álbum Txai, em 1990. O nome da música faz referência ao Ashaninka Benke Piyâko, encontrado ainda menino pelo cantor Milton Nascimento em uma de suas visitas à Amazônia brasileira acreana. O indígena, agora adulto, é um dos personagens citados na reportagem de Vinícius Dônola.

3 Telejornal de abrangência nacional que vai ar ao de segunda a sábado de 19h45 as 20 h30 na Record TV.

4 Segundo Evanildo Bechara (2002), "por convenção internacional de etnólogos, está há anos acertado que, em trabalhos científicos, os etnônimos que não sejam de origem vernácula ou nos quais não haja elementos vernáculos não são alterados na forma plural, sendo a flexão indicada pelo artigo plural: os tupi, os nambiquara, os caiuá, os tapirapé, os bântu, os somali, etc." (BECHARA, 2002 apud MANUAL DE REDAÇÃO OFICIAL DA FUNAI, 2016, p. 19). Desse modo, opta-se neste artigo científico pela utilização dos nomes das etnias no singular. Elas aparecem pluralizadas somente nas falas do repórter Vinícius Dônola.

5 Informações disponíveis em: https://cpiacre.org.br/ashaninka/. Acesso em: 28 de dezembro de 2020.
} 
O objetivo deste artigo é discutir de que forma esta reportagem televisiva articula as representações sobre os povos indígenas Ashaninka, que vivem na fronteira Brasil-Acre/Peru, e a Amazônia brasileira acreana. A escolha deste produto televisivo se deu por fazer parte de um conjunto de reportagens que foram ao ar em rede nacional somente sobre o Acre. Este estado nortista não é pauta frequente na televisão brasileira, por isso a importância da série de reportagens, apesar de já passados sete anos de sua veiculação na TV.

Este estudo está vinculado ao grupo de pesquisa Mídias, Imaginário e Representação: uma cartografia das Amazônias (MIRCA) cadastrado na Plataforma dos Grupos do CNPq desde 2016, que, por sua vez, pretende discutir as representações e os imaginários a respeito da Amazônia brasileira e de sua gente, construídos pela narrativa dos mais diversos tipos de mídias.

A pesquisa tem cunho bibliográfico e usa como suporte os seguintes autores: Homi Bhabha (2013), Manuela Carneiro Cunha (2012, 2016), Gerson Albuquerque (2016), entre outros. Os seguintes aspectos de análise são levados em consideração como percurso metodológico: inferno/paraíso tropical; as noções de vazio, monotonia e distanciamento; e a comparação dos espaços floresta/cidade não amazônica. Esses aspectos são analisados, pois são recorrentes em narrativas sobre a Amazônia acreana, como discutido no item 2 deste artigo. Todos esses pontos se articulam em torno das ideias de atraso/progresso, tradição/ moderno, presente/passado que permeiam a formação da Amazônia brasileira acreana e de suas gentes, sobretudo, indígenas.

\section{Jornalismo e representações}

A prática da representação é muito importante nos Estudos Culturais, passando a ocupar lugar no estudo sobre a cultura, pois "a representação conecta o sentido e a linguagem à cultura" (HALL, 2016, p. 31). Segundo Murilo César Soares (2009), as representações aparecem no contexto discursivo como formas casuais, meras insinuações, "pistas" visuais, ou mesmo como "cenário" dado como "normal" ou "padrão”, o que acaba naturalizando a representação. 
Para Miquel Rodrigo Alsina (2009), a notícia - o que se aplica também ao gênero reportagem - é uma representação social da realidade cotidiana e que se manifesta na construção de um mundo possível. Ela gera sentido e noção de organização da "realidade", estando "intimamente ligada à identidade e conhecimento" (HALL, 2016, p. 25). Por isso, ao ler/ver/ouvir determinada informação, as pessoas passam a atribuir sentido e fazer associações entre o que foi publicado nos meios de comunicação e o acontecido. Ainda no pensar de Hall (2016): "O principal ponto é que o sentido não é inerente às coisas, ao mundo. Ele é construído, produzido. É o resultado de uma prática significante, uma prática que produz sentido, que faz os objetos significarem" (HALL, 2016, p. 46).

O autor (2016) segue afirmando ainda que a representação produz o entendimento social, sendo parte essencial do processo pelo qual "os significados são produzidos e compartilhados entre os membros de uma cultura. Representar envolve o uso da linguagem, de signos e imagens que significam ou representam objetos" (HALL, 2016, p. 31).

No tocante à Amazônia acreana, percebe-se que algumas informações jornalísticas noticiadas sobre os povos indígenas ainda se concentram em destacar suas "relações com a natureza, a ocupação de terras férteis, ou a presença indígena como atrapalho para a realização de atividades consideradas lucrativas, dando contornos de exotismo, retrocesso e primitivismo" (MENDES, 2019). Essas representações excluem, limitam e restringem, muitas vezes, outras leituras a respeito da região amazônica e de seus povos tradicionais, pois, principalmente, as imagens reproduzidas na TV ganham status de "verdade" para o público.

\section{Amazônia(s): os indígenas sob a ótica dos viajantes}

Os cronistas de viagem que chegaram à Amazônia no século XVI foram responsáveis pelos primeiros relatos a respeito da região e das pessoas que nela viviam, dentre os mais importantes citam-se Frei Gaspar de Carvajal (1541-1542 - Descobrimento do rio de Orellana), Alonso de Rojas (1639 - Descobrimento do Rio das Amazonas e suas dilatadas províncias) e Christóbal de Acuña (1641 - Novo descobrimento do rio 
das Amazonas). No dizer de Ana Pizarro (2012), os viajantes/cronistas vão encontrar o que o imaginário deles já havia criado, antes mesmo de saírem da Europa:

Para o viajante, o que espera ver e encontrar já havia sido ditado por suas leituras, seus temores, suas fantasias, toda a informação fabulosa que reuniu em seu meio. De algum modo, ele vai encontrar o que esperava encontrar, o que imagina de alguma maneira já está em sua cabeça. Daí sairá o imaginário de gigantes, anões, a monstruosidade do cinocéfalo [que tem cabeça ou face de cachorro], do bispo do mar, dos homens com rabo, dos orelhões (PIZARRO, 2012, p. 67-68).

Ao longo dos últimos cinco séculos, a ideia de Amazônia foi construída, predominantemente, pelo pensamento externo aos que nela vivem. A região tem sido pensada através de imagens construídas, principalmente, pelos europeus, sobre o que eles entendem a respeito da região e de suas gentes. Por isso, o conceito de Amazônia é resultado de uma construção discursiva (PIZARRO, 2012). Apesar de a região abranger nove países (Brasil, Peru, Colômbia, Bolívia, Equador, Suriname, Venezuela, Guiana e Guiana Francesa), ela é historicamente narrada de forma singular, homogênea e uniforme, é como se a paisagem fosse única e todos os povos que ocupam esta porção de terra pensassem e se comportassem da mesma forma, sem tensões e/ou diferenças sociais, políticas, históricas, econômicas, culturais.

De acordo com o pensamento de Miguel Nenevé e Sônia Sampaio (2015), muitos discursos não se preocupam em tratar sobre a enorme diversidade nem a dinâmica das culturas que povoam as Amazônias. "Sim, existem povos indígenas, existem sistemas antigos de povoamentos pré-colombianos, como também existe uma Amazônia multiétnica, multicultural, que passa por uma mudança dinâmica" (2015, p. 20).

De um modo geral, a Amazônia no singular é vista como um lugar exótico, vazio, distante, que pode ser ao mesmo tempo inferno e paraíso, e quando é ocupada, é por não civilizados (indígenas e não indígenas). Mas é importante que se diga que ela não "estava ali desde sempre, como obra da natureza acabada" (ALBUQUERQUE, 2016, p. 79). Com o tempo, "foram sendo produzidas imagens, metáforas e tratados científicos sobre 'sociedade' e 'natureza' que concorreram para a 'invenção da Amazônia' enquanto região homogênea” (ALBUQUERQUE, 2016, p. 80). 
No caso da reportagem de Dônola, é possível perceber a manutenção de algumas dessas concepções seculares a respeito dos signos "Amazônia", "povos indígenas". Em 14'25", o jornalista apresenta seu "estoque de verdades" (ALBUQUERQUE, 2016, p. 85) sobre a etnia Ashaninka e a Amazônia brasileira acreana.

A reportagem inicia com a cabeça da matéria, o que no jargão jornalístico significa o texto lido pelos apresentadores do jornal como uma espécie de introdução da reportagem. A seguir, o texto proferido pelos jornalistas Celso Freitas e Adriana Araújo, âncoras do Jornal da Record:

Em um Brasil quase desconhecido, homens gigantes vivem na floresta no extremo oeste do Acre próximo à fronteira do Brasil com o Peru. São os índios Ashaninka. Um povo originário dos incas peruanos, que habita várias aldeias da Amazônia e tem costumes diferentes de outras tribos indígenas (FREITAS; ARAÚJO, 2013).

"Brasil quase desconhecido", "homens gigantes", "extremo oeste", "costumes diferentes" são termos que ajudam a criar "realidades" e "verdades" (ALBUQUERQUE, 2016, p. 83) sobre o Acre e essa comunidade Ashaninka. Como dito em outros trabalhos sobre representação a respeito da Amazônia brasileira acreana e dos povos originários, desde as primeiras narrativas escritas sobre a Amazônia e o estado do Acre, há marcas da "dicotomia inferno/paraíso tropical e as mais diversas populações amazônidas (indígenas e não indígenas) são identificadas, muitas vezes, como signo do exotismo e do atraso" (MENDES, 2019)6.

A matéria inicia somente com imagens do amanhecer em meio à floresta, sem a fala do repórter. Céu nublado e acinzentado em um cenário de construções de moradias cobertas com folhas de palmeiras, ao fundo uma trilha sonora musical de tensão e a ideia de que a qualquer momento algo inesperado pode acontecer em meio aquele lugar chamado de "última fronteira", "desconhecido" e "muito distante" (DÔNOLA, 2013). O paraíso pode se tornar um inferno rapidamente. Ao iniciar o off, que no fazer jornalístico é a locução coberta por imagens, a descrição da paisagem organiza o discurso a respeito da região. Em outras palavras, é um procedimento discursivo de grande importância para uma apropriação do território, sua representação e formação.

6 Trecho extraído do texto intitulado Representações sobre os povos indígenas no jornalismo do G1/Acre (2013 a 2018) apresentado no XIII LIA - Linguagens e Identidades das/nas Amazônias, evento que ocorreu entre os dias 7 a 9 de novembro de 2019, na Universidade Federal do Acre - UFAC. 
As primeiras imagens, ainda no caminho para a aldeia, destacam uma paisagem horizontal filmada a partir de uma embarcação movida a motor, mas que se desloca lentamente no rio com a equipe de reportagem. Na passagem do repórter, quando ele fala diretamente aos telespectadores, há uma narrativa de superação e dificuldades da equipe para se chegar à comunidade indígena: "desviamos de galhos e troncos imensos, a viagem é lenta e tem imprevistos" (DÔNOLA, 2013).

Na reportagem, destaque-se que o rio Amônia está seco e que a viagem de barco, entre a cidade de Marechal Thaumaturgo e a aldeia Ashaninka, é lenta. O jornalista deixa claro seu estranhamento com a embarcação e com o fato da viagem até a aldeia Ashaninka ser longa (3 horas e 50 minutos). Apesar disso, estrangeiros/jornalistas precisam entender que "os rios são práticas culturais", (ALBUQUERQUE, 2016, p. 86), "os rios são estrada obrigatória" (TOCANTINS, 1982, p. 7) nas Amazônias e, por vezes, não tem como se deslocar no interior da mata sem percorrê-los.

Em Euclides da Cunha (1999), a Amazônia já era vista de forma singular, monótona e horizontal, e constantemente dicotômica (paraíso/ inferno tropical), como observado na passagem a seguir:

o maior quadro da terra; porém, chatamente rebatido num plano horizontal (...) à feição de uma enorme moldura que se quebrou (...) E como Ihe falta a linha vertical, preexistente na movimentação da paisagem, em poucas horas o observador cede às fadigas de monotonia inaturável e sente que o seu olhar, inexplicavelmente, se abrevia nos sem-fins daqueles horizontes vazios e indefinidos como os dos mares (CUNHA, 1999, p. 1-2).

Além da ideia de monotonia, as ideias de vazio e distanciamento também estão presentes na reportagem especial da Record TV, como quando o repórter diz: "só depois de três horas e meia de navegação, encontramos sinais da presença dos índios, e agora sim, os primeiros Ashaninka na margem do rio" (DÔNOLA, 2013). Como quem (re)descobre os indígenas no século XXI, o repórter os encontra finalmente à margem do rio. Eles ocupam o vazio amazônico, aquele vazio dos primeiros cronistas que não era "de mulheres e homens, e sim de humanidades e culturas, de capacidade de pensar e raciocinar" (ALBUQUERQUE, 2016, p. 81). O autor complementa: 
Dentre essas palavras/conceitos destacamos a noção de 'vazio', que se constituiu como um dos mais poderosos mitos de justificativa para toda a sorte de violências físicas e simbólicas no processo de expansão da economia, política, religiosidade, organização social, das artes e línguas europeias para essa parte dos mundos não-europeus (ALBUQUERQUE, 2016, p. 81).

A Amazônia nunca foi "terra sem história" (CUNHA, 1999), nunca foi um vazio nem de sentido e nem demográfico, como também afirma Márcio Souza:

Quando os europeus chegaram, no século XVI, a Amazônia era habitada por um conjunto de sociedades hierarquizadas, de alta densidade demográfica, que ocupavam o solo com povoações em escala urbana, possuíam sistema intensivo de produção de ferramentas e cerâmicas, agricultura diversificada, uma cultura de rituais e ideologia vinculadas a um sistema político centralizado e uma sociedade fortemente estratificada. Essas sociedades foram derrotadas pelos conquistadores, e seus remanescentes foram obrigados a buscar a resistência, o isolamento ou a subserviência. O que havia sido construído em pouco menos de 10 mil anos foi aniquilado em menos de 100 anos, soterrado em pouco mais de 250 anos e negado em quase meio milênio de terror e morte (SOUZA, 2015, p. 37).

Em outro momento da reportagem (9'20"), o jornalista afirma que uma "densa neblina cobre a aldeia, o sol parece mais preguiçoso quando nasce na Amazônia” (DÔNOLA, 2013). O indígena preguiçoso que habita um local igualmente preguiçoso é uma ideia ligada ao processo de formação social e histórico da região amazônica brasileira e acreana e de suas gentes. No século XVIII, por exemplo, o cientista francês La Condamine (2000) em viagem à Amazônia relatou que os indígenas eram inimigos do trabalho, sem preocupação com o futuro e incapazes de reflexão.

Os primeiros europeus que chegaram ainda no século XVI não entendiam/não aceitavam as formas de trabalho dos mais diversos povos encontrados, a vida em sociedade e seus aspectos culturais, por isso os indígenas foram considerados selvagens e não civilizados: "a ideia de que os brancos europeus podiam sair colonizando o resto do mundo estava sustentada na premissa de que havia uma humanidade esclarecida que precisava ir ao encontro da humanidade obscurecida, trazendo-a para essa luz incrível" (KRENAK, 2019, p. 11). 
Essa humanidade esclarecida e civilizada era formada por homens brancos europeus. Nas primeiras décadas do século XXI, o estrangeiro que chega à Amazônia, mesmo sendo brasileiro, se sente meIhor, superior ao amazônida e, logo, também quer "nomear", "explicar", "ensinar", "colonizar" os autóctones.

Ao longo dos séculos de colonização, foi atribuída aos povos originários uma ideia de que não tinham disponibilidade para o trabalho, quando, na verdade, o que eles não queriam é viver a escravidão imposta pelos estrangeiros (portugueses, espanhóis, franceses, ingleses, entre outros) e/ou se render às exigências do mundo capitalista. Segundo Cunha (2012):

Declarada ou embuçada porém, a escravidão indígena perdurou supreendentemente até pelo menos os meados do século XIX. Vendiam-se crianças (Circular 9/8/1845) e adultos eram disfarçadamente escravizados também (Aviso 2/9/1845). No que é hoje o Amazonas, a escravização nas formas mais tradicionais - apresamento direto, estímulo à guerra indígena para compra de prisioneiros - continuava como se nada houvesse (Hemming 1987: 211-20). Mas até na corte se encontravam escravos índios até pelo menos 1850! Nessa data, o viajante americano Thomas Ewbank anota: 'os índios aparecem para serem escravizados tanto quanto os negros; no Rio muitos deles têm sido negociados'. Durante a seca do Ceará, os pais venderiam seus filhos, seguindo um procedimento inaugurado no século XVI: 'Antes era muito difícil conseguir um indiozinho por menos de setenta mil réis, mas agora os seus pais, não tendo nada que comer, oferecerem-nos de bom gosto por dez' (Ewbank 1850: 242) (CUNHA, 2012, p. 82-83).

No final do século XIX e início do XX, essa representação foi mais uma vez acentuada durante o primeiro ciclo da borracha na Amazônia, quando os indígenas novamente não se adequaram à exploração imposta pelo sistema de coleta do látex. A mão de obra indígena foi uma alternativa transitória até que se estabelecesse a imigração de trabalhadores nordestinos (CUNHA, 2012), sobretudo, a partir de 1877, quando o Ceará viveu um período de grande seca?

\footnotetext{
7 Segundo Albuquerque Junior, essa só foi considerada uma grande seca, pois atingiu a elite: "Enquanto a seca matava apenas animais, escravos e homens pobres, ela nunca havia sido considerada um grande problema, nunca havia despertado tanta atenção, seja nos discursos parlamentares, seja nos documentos oficiais, seja na imprensa. (...) Ela, pela primeira vez, atinge com intensidade setores médios dos proprietários de terras, com a falência de alguns, a morte ou a necessidade de migração para outros. A própria existência de uma imprensa mais organizada e com capacidade de repercutir o fenômeno em nível nacional, algo que não ocorreu em secas anteriores, dá uma repercussão a esta seca como não fora dada a nenhuma outra anterior" (ALBUQUERQUE JUNIOR, 2012, p. 93).
} 
Além dessas ideias essencializadas, há outro aspecto evidente nas narrativas sobre a Amazônia que é a comparação entre os espaços floresta/cidade não amazônica. Diz-se "cidade não amazônica", pois os aspectos urbanos amazônicos não são levados em consideração nas narrativas sobre essa região brasileira. Há uma necessidade dos jornalistas/viajantes/narradores especificarem que a floresta não é moderna, não é confortável e que a cidade não amazônica apresenta mais recursos e mais possibilidades de sobrevivência. Como bem enfatiza Nenevé e Sampaio, "há a Amazônia urbana como há um amplo conjunto de comunidades isoladas. São histórias heterogêneas, conhecimentos científicos variados, intersecção de histórias indígenas com a dos colonizadores" (2015, p. 20).

Na reportagem de Dônola, a Ashaninka Alexandrina é entrevistada e fala sobre suas experiências na cidade de São Paulo. Ela diz não ter se adaptado, pois a vida urbana é "muito diferente" e ela se "sentia presa". Por meio da fala da personagem, o jornalista enfatiza essa oposição floresta/cidade não amazônica. A não adaptação é vista como uma incapacidade, uma incivilidade dos sujeitos que vivem no meio da floresta amazônica e não apenas como o direito de ter outras possibilidades de vida, outras formas de ser, dizer e saber longe dos espaços urbanos não amazônicos.

Dônola destaca ainda que a comunidade Ashaninka não aceitou o gerador de luz elétrica dado pela prefeitura do município mais próximo da aldeia, Marechal Thaumaturgo - Acre. Segundo o off do repórter, os indígenas "optaram por viver como no passado, de forma consensual, eles abriram mão de certas comodidades da vida moderna" (DÔNOLA, 2013). As narrativas sobre a Amazônia e suas gentes estão presas a um suposto passado, por isso Márcio Souza afirma que é um desafio à inserção dos indígenas "numa cultura que se globaliza a partir das matrizes dominantes” (SOUZA, 2015, p. 16), pois ou eles são vistos como ameaçadores ou são interpretados como atrasados por supostamente rejeitar a modernidade, como bem afirma Almeida (2009):

as histórias que se desenvolveram valorizaram os índios do passado e não incorporavam os do presente que, aos olhos dos intelectuais e políticos, apresentavam-se de duas maneiras: como degradados pela exploração colonial, que deviam ser civilizados e integrados aos Estados como cidadãos; ou selvagens em estado primitivo, que deviam, também, ser incorporados ou combatidos, caso mantivessem as hostilidades (2009, p. 215). 
No off de Dônola: "ele [o cacique] e outros líderes da aldeia hoje entendem que não se pode mais fechar os olhos para o mundo moderno". E, então, pergunta-se: as lideranças estavam de olhos fechados? E o que seria o mundo moderno para o jornalista? Será que o mundo moderno do jornalista interessa àquela comunidade específica? O que os indígenas Ashaninka entendem por mundo moderno? São muitas as perguntas, porém, sabe-se apenas que a não familiaridade com culturas diferentes passa sempre pelo julgamento do outro.

Por exemplo, no que a luz elétrica beneficiaria os afazeres cotidianos dos povos indígenas (plantação, caça, produção de túnicas, aulas na escola etc)? A energia é realmente necessária para a comunidade visitada? Provavelmente, não. Caso contrário, já estariam fazendo uso desse serviço. Em contrapartida, a matéria evidencia o uso de energia solar para que os líderes indígenas possam acompanhar via internet, por meio de satélites, o desmatamento de suas terras e as possíveis invasões. Assim, quando detectado algo de errado, eles podem acionar as autoridades competentes a tempo de evitar maiores problemas em suas terras. Como sujeitos de suas histórias, eles decidem o que é importante e quais são suas necessidades, não estando, portanto, preocupados em se adequar aos conceitos de modernidade do estrangeiro.

É preciso repensar a história contada sobre as mais diversas etnias no Brasil, não as limitando a dicotomia atraso/progresso, tradição/moderno, presente/passado, floresta/cidade não amazônica. Não existe uma história única nem da(s) Amazônia(s) e nem dos povos indígenas. Fazendo uso do pensamento de Adichie (2019), ela afirma que as histórias podem ser usadas para empoderar e humanizar, pois podem despedaçar a dignidade de um povo, mas também podem reparar essa dignidade despedaçada. A autora completa dizendo que: "quando rejeitamos a história única, quando percebemos que nunca existe uma história única sobre lugar nenhum, reavemos uma espécie de paraíso" (ADICHIE, 2019, p. 33).

O jornalista/viajante/narrador tem dificuldade de conceber uma nova forma de vida que não seja a sua, por isso a comunidade é distante, o barco é lento, o sol é preguiçoso, a falta de luz elétrica significa viver no passado. Diante disso, as Amazônias e seus povos seguem um espaço culturalmente marginal (SOUZA, 2015), sendo necessário pensar "além das narrativas de subjetividades originárias e iniciais e de focalizar aqueles momentos ou processos que são produzidos na articulação de diferenças culturais" (BHABHA, 2013, p. 20). 
Essas dificuldades vividas por Dônola explicam o que Bhabha afirma ser um embate de fronteira acerca da diferença cultural, pois esse encontro com o diferente tem a possibilidade de ser consensual, mas também pode ser conflituoso; pode confundir "nossas definições de tradição e modernidade, realinhar as fronteiras habituais entre o público e o privado, o alto e o baixo, assim como desafiar as expectativas normativas de desenvolvimento e progresso" (BHABHA, 2013, p. 21).

O embate com a diferença cultural também é percebido na reportagem pela excessiva ênfase ao fato de que os Ashaninka usam túnica (kitharêtsi), como na passagem a seguir: "desde cedo, meninos e meninas usam túnicas até para brincar, mas a mulher do cacique sempre preferiu as saias e outras roupas convencionais" (DÔNOLA, 2013). Quanto a isso, é possível fazer uma inferência: as roupas indígenas não são convencionais na opinião do jornalista, pois, para ele, o convencional seria encontrar o indígena vestido como imagina ser adequado ou sem roupa, com o corpo pintado e com adornos. Essa segunda ideia vem desde a carta de Pero Vaz de Caminha, quando os primeiros homens e mulheres foram descritos sem o uso de roupa, com suas "vergonhas" de fora. Essa imagem de nudez em Caminha está associada, segundo Cunha, "a ideia de inocência" (CUNHA, 2012, p. 30), mas não se concretiza na reportagem exibida na Record TV, pois os Ashaninka aparecem sempre vestidos.

Ao relatar o uso da túnica, a reportagem apresenta uma tensão na fala da mulher do cacique Antônio Piyâko, dona Francisca Oliveira. Ela não é Ashaninka, por isso não usa túnica, pois, segundo a não indígena, essa é "a roupa das índias" e não dela. De acordo com o jornalista, ela usa "roupas convencionais", ou seja, saias e vestidos. A fala desta senhora enfatiza que nem os próprios indígenas ou aqueles que vivem juntos nas mesmas comunidades usam as mesmas vestes, e apresentam uniformidade de pensamentos, logo é desaconselhável pensar que uma sociedade organizada como a dos Ashaninka é toda igual ou que todas as etnias que vivem no Acre agem de forma homogênea, simplista e singularizada. Segundo Cunha:

Se há semelhanças, sem dúvida, entre sociedades indígenas no Brasil, até entre aquelas distantes no espaço e linguisticamente, essas conexões não resultam em homogeneidade. Não se podem generalizar conclusões, como alerta Clarice Cohn neste livro. Essas sociedades são diferentes da(s) nossa(s) e também diferentes entre si (CUNHA, 2016, p. 9-10). 
De acordo com Maria Regina Celestino de Almeida (2009), esse processo de homogeneização implica na invisibilização das identidades indígenas "com o propósito de eliminar qualquer forma de diversidade que não se traduzisse em termos sociais" (ALMEIDA, 2009, p. 212). Todavia, Mignolo (2008) ressalta que os povos indígenas não são homogêneos, pois possuem, entre outras coisas, línguas e crenças diferentes umas das outras, sendo necessário, portanto, um "desprendimento do pensamento do eurocentrismo como esfera do conhecimento, a partir do qual é possível controlar a economia, a autoridade, o gênero e a sexualidade, em suma, a subjetividade" (MIGNOLO, 2008, p. 242).

Outro assunto relevante mencionado na reportagem é a presença da escola indígena naquela comunidade, onde diretor, professor e aluno são todos Ashaninka. Assim, faz-se uso da língua da etnia e estuda-se um conteúdo adequado aos interesses daquele povo específico. Segundo a matéria, a escola tem 175 estudantes que cursam ensino fundamental e médio. Segundo Cunha (2016), a escolarização indígena tem seus impasses, por exemplo,

\begin{abstract}
'alfabetizar' povos indígenas em sua língua vernacular é, supondo que o escrito vale mais do que o falado, 'elevar' as línguas indígenas. (...) Mas as línguas indígenas no Brasil são originalmente sem escrita, ágrafas. A adoção de um regime escrito para elas pode resultar em uma desvalorização ainda mais radical de um regime de transmissão oral que impera não somente nas línguas, como em muitos outros campos do conhecimento (Ladeira) (CUNHA, 2016, p. 17).
\end{abstract}

A reportagem não problematiza nem essas questões e nem outras questões sobre o ensino indígena, se concentra somente em citar exemplos de alguns fonemas da língua dos Ashaninka que não são comuns na língua portuguesa.

Apesar de muitas informações importantes que são evidenciadas no jornalismo produzido pela Record TV, não houve uma preocupação em explicar a história de luta deste povo, especificar que essas pessoas vivem não só no Brasil, mas também no Peru e na Bolívia. E que aquela comunidade retratada não representa as demais pessoas da mesma etnia que vivem em outro local no Acre, ou até mesmo em outro país.

Cita-se como exemplo o uso do termo "gigante" ou ainda "gigantes que vestem túnica" para designar os Ashaninka. Do modo como posto, eles são colocados de "forma desproporcional" (BHABHA, 2013, p. 126) 
para o público, como se faz comumente com os povos colonizados. $\mathrm{Na}$ verdade, naquela comunidade específica, há dois homens considerados altos, Benke e Moisés, filhos do cacique -, que têm, respectivamente, $1,85 \mathrm{~cm}$ e $1,90 \mathrm{~cm}$ de altura. Diante disso, o termo "gigante" além de exagerado, só poderia se aplicar a essas duas pessoas específicas e não a outros membros da mesma comunidade ou a membros de outra comunidade de mesma etnia. Por isso, "a necessidade urgente de contestar singularidades de diferença e de articular 'sujeitos' diversos de diferenciação" (BHABHA, 2013, p. 128) quando se discute sobre a vida e o comportamento cotidiano de pessoas que fazem parte de comunidades de povos originários.

O jornalismo não pode tentar anular as multiplicidades e as diferenças individuais em nome de reducionismos, por isso Gersem dos Santos Luciano argumenta que:

Cada povo indígena constitui-se como uma sociedade única, na medida em que se organiza a partir de uma cosmologia particular própria que baseia e fundamenta toda a vida social, cultural, econômica e religiosa do grupo. Deste modo, a principal marca do mundo indígena é a diversidade de povos, culturas, civilizações, religiões, economias, enfim, uma multiplicidade de formas de vida coletiva e individual (LUCIANO, 2006, p. 31).

Diante disso, é função do jornalismo exemplificar essas diferenças entre indígenas e não indígenas e até mesmo entre os próprios grupos indígenas não como algo inusitado, mas como parte das diversidades e pluralidades da vida em sociedade. Assim, o jornalismo precisa lutar "contra a opressão colonial" não apenas mudar a direção da história ocidental, mas também contestar "sua ideia historicista de tempo como um todo progressivo e ordenado" (BHABHA, 2013, p. 79).

\section{Considerações finais}

Como dito na Introdução deste artigo, o Acre e suas populações não são frequentemente pauta na mídia tradicional brasileira. Portanto, destaca-se a iniciativa do jornalista Vinícius Dônola em ouvir as vozes que habitam a região norte do país por meio da série de reportagem "A última fronteira". 
Apesar desse movimento em direção às margens, o jornalismo precisa modificar alguns conceitos a respeito dos povos indígenas presentes na Amazônia brasileira acreana, tais como: noções de inferno-paraíso tropical; ideia de vazio, monotonia e distanciamento; comparação dos espaços floresta/cidade não amazônica. Essas perspectivas resistem secularmente nas narrativas a respeito das Amazônia(s) e de suas populações, que são interpretadas negativamente como tradicionais, atrasadas e vivendo no passado.

O povo Ashaninka precisa ser pensado como produtor de culturas, de linguagens, de pensamentos. O Acre não é somente a "última fronteira", "Brasil quase desconhecido", "extremo oeste", mas é, especialmente, espaço de pluralidades culturais, de formas de resistência e multiplicidades de, pelo menos, 17 etnias $^{8}$. "Quando falamos, no plural, sobre culturas, bem como de Amazônia(s), queremos enfatizar a necessidade de desmantelar a visão única sobre a Amazônia" (NENEVÉ; SAMPAIO, 2015, p. 20). Para tanto, deve-se se distanciar dos significados já postos que envolvem os processos de homogeneização, dos estereótipos, do conceito de exotismo e das dicotomias limitadoras.

O discurso que afirma ser a Amazônia brasileira acreana uma região onde impera o atraso, a degeneração e a passividade constrói a noção de que esta terra sempre precisará ser dominada por "estrangeiros", pelos "outros", pois os autóctones, principalmente, os indígenas, nunca estarão aptos a fazer avanços e progredir sem a intervenção dos 'de fora'.

Dessa forma, o presente estudo sugere a ampliação e a (re)construção de outros olhares das narrativas jornalísticas sobre essa região e a população Ashaninka. Os jornalistas precisam indicar novas perspectivas a respeito do assunto, sobretudo, àquelas que valorizam as particularidades e as reais necessidades dessa e de outras comunidades que habitam os vários Brasis existentes.

8 Segundo o documento Acre em números 2017, existe no estado uma população de 19.962 indígenas vivendo em 209 aldeias. As etnias presentes no estado são: Jaminawa, Manchineri, Huni Kuin, Kulina, Ashaninka, Shanenawa, Yawanawá, Katukina, Sayanawa, Jaminawa-Arara, Apolima-Arara, Shawãdawa, Puyanawa, Nukini, Nawas, Sayanawa e os "isolados" 


\section{REFERÊNCIAS}

ADICHIE, Chimamanda Ngozi. O perigo da história única. Tradução de Julia Romeu. São Paulo: Companhia das Letras, 2019.

ALBUQUERQUE, Gerson. Amazonialismo. In: ALBUQUERQUE, Gerson; PACHECO, Agenor Sarraf. Uwa'kürü Dicionário Analítico. Rio Branco - Acre, Editora Nepan, 2016.

ALMEIDA, Maria Regina Celestino de. O lugar dos índios na história entre múltiplos usos do passado: reflexões sobre cultura histórica e cultura política. In: SOIHET, Raquel (org.). et al. Mitos, projetos e práticas políticas: memória e historiografia. Rio de Janeiro: Civilização Brasileira, 2009.

ALSINA, Miquel Rodrigo. A construção da notícia. Petrópolis: Vozes, 2009

BHABHA, Homi K. O local da cultura. Tradução Myriam Ávila. Belo Horizonte: Editora UFMG, 2013.

CUNHA, Euclides. À Margem da História. São Paulo: Martins Fontes, 1999.

CUNHA, Manuela Carneiro da. Índios no Brasil: história, direitos e cidadania. São Paulo: Claro Enigma, 2012.

CUNHA, Manuela Carneiro da. Políticas culturais e povos indígenas - uma introdução. In: CUNHA, Manuela Carneiro da; CESARINO, Pedro de Niemeyer (org.). Políticas culturais e povos indígenas. São Paulo: Editora Unesp, 2016.

DÔNOLA, Vinícius. A Última Fronteira: direto do Acre, conheça os índios Ashaninka. 2013, 14'25", son., color. Disponível em: https://www.youtube.com/watch?v=8kqGwrcY0Q0\&t=97s. Acesso em: 20 de janeiro de 2018.

FREITAS, Celso; ARAÚJO, Adriana. Cabeça da matéria A Última Fronteira: direto do Acre, conheça os índios Ashaninka. 17", son., color. Disponível em: https://www.youtube.com/watch?v=8kqGwrcYOQ0\&t=97s. Acesso em: 20 de janeiro de 2018.

HALL, Stuart. Cultura e representação. Tradução de Daniel Miranda e William Oliveira. Rio de Janeiro: Ed. PUC-Rio: Apicuri, 2016.

KRENAK, Ailton. Ideias para adiar o fim do mundo. São Paulo: Companhia das Letras, 2019.

LA CONDAMINE, Charles-Marie de. Viagem na América Meridional descendo o rio das Amazonas. Brasilia: Senado Federal, 2000.

LUCIANO, Gersen dos Santos. O Índio Brasileiro: o que você precisa saber sobre os povos indígenas no Brasil de hoje. Brasília: Ministério da Educação, Secretaria de Educação Continuada, Alfabetização e Diversidade, 2006.

MANUAL DE REDAÇÃo OFICIAL DA FUNAI. Organizado pela Comissão Especial de Elaboração do Manual - Portaria n. 540/2015/ Pres-Funai. - Brasília: Funai, 2016.

MIGNOLO, Walter. Novas reflexões sobre a 'idéia da América Latina': a direita, a esquerda e a opção descolonial. Caderno CRH, Salvador, v. 21, n. 53, p. 239-252, maio/ago. 2008.

MENDES, Francielle. Representações sobre os povos indígenas no jornalismo do G1/Acre (2013 a 2018). Trabalho apresentado no XIII LIA - Linguagens e Identidades das/nas Amazônias.

Rio Branco: UFAC, 2019. 
NENEVÉ, Miguel; SAMPAIO, Sônia. Re-imaginar a Amazônia, descolonizar a escrita sobre a reigão. In: ALBUQUERQUE, Gerson; NENEVÉ, Miguel; SAMPAIO, Sônia. Literaturas e Amazônias: colonização e descolonização. Rio Branco: Nepan, 2015.

PIZARRO, Ana. Amazônia: as vozes do rio. Tradução Rômulo Monte Alto. Belo Horizonte: Editora UFMG, 2012.

SEPLAN. Acre em números 2017. Rio Branco, 2017

SOARES, Murilo César. Representações, jornalismo e a esfera pública democrática. São Paulo: Cultura Acadêmica, 2009.

SOUZA, Márcio. Amazônia Indígena. Rio de Janeiro: Record, 2015.

TOCANTINS, Leandro. Amazônia - Natureza, Homem e Tempo: uma planificação ecológica. Rio de Janeiro: Civilização Brasileira, 1982.

Recebido em: 08/05/20

Aprovado em: 19/03/21 


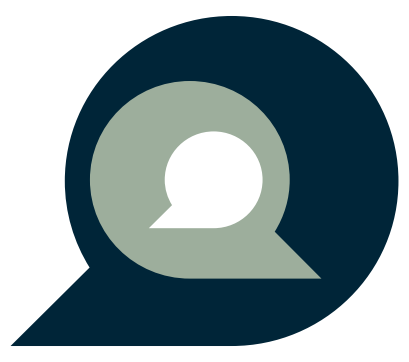

